\title{
Measurement of the motility of rat spermatozoa collected by micropuncture from the testis and from different regions along the epididymis
}

\author{
B. T. Hinton, H. M. Dott and B. P. Setchell \\ Department of Biochemistry and Animal Research Station, A.R.C. Institute of Animal \\ Physiology, Babraham, Cambridge CB2 4AT, U.K.
}

\begin{abstract}
Summary. Spermatozoa from the testis and various regions along the epididymis of the rat were collected by micropuncture and their motility after dilution was estimated over a 15 -min period by using a Quantimet image analyser. The motility of spermatozoa from the rete testis and seminiferous tubules was too low to be measured. The estimate of motility of spermatozoa from the proximal caput epididymidis was much lower than that of spermatozoa from the other regions. Spermatozoa from the distal part of the caput showed sustained motility for 15 min, whereas those from the caudal region and ductus deferens, although active initially, became less active during this period.
\end{abstract}

\section{Introduction}

Spermatozoa are virtually immotile when they leave the testis but acquire the capacity for movement during their stay in the epididymis. The pattern of sperm motility in various regions of the epididymis has been studied in several species (Tournade, 1913; Blandau \& Rumery, 1964; Gaddum, 1968; Fray, Hoffer \& Fawcett, 1972; Burgos \& Tovar, 1974), but there have been relatively few studies concerned with the measurement of the motility of spermatozoa from distinct sites along the mammalian epididymis. This is probably due to the lack of adequate instruments designed to quantify sperm motility and also of techniques available for obtaining samples of spermatozoa from distinct areas along the epididymis. It is important that these samples should be free from tissue, blood and other extracellular fluids which possibly interfere in the measurements of motility. Micropuncture techniques, used extensively by many kidney physiologists, have been applied to the male reproductive tract in order to collect samples free from contamination, but the only previous study known to us which has used micropuncture techniques to study the motility of the epididymal spermatozoa from the rat is that by Wyker $\&$ Howards (1977), in which three sites were chosen and motility was measured by assessing the percentage of spermatozoa motile in each sample.

The present investigation was undertaken to study the precise area in the caput epididymidis of the rat where the potential for motility of spermatozoa begins and to compare the degree of motility of spermatozoa removed from distinct sites along the epididymis.

\section{Materials and Methods}

\section{Animals}

Adult male Porton-Wistar rats weighing 350-450 g were obtained from the Institute colony where they were housed under $14 \mathrm{~h}$ daylight and had free access to food (Oxoid breeding diet) and water. 


\section{Micropuncture}

The rats were anaesthetized by an intraperitoneal injection of urethane (ethyl carbamate, 1.2 $\mathrm{mg} / \mathrm{kg}$ ). One testis and epididymis were exposed through a scrotal incision, placed into a Perspex cup holder and the tissue secured in position with agar (Ullrich, Frömter \& Bauman, 1969). Tubules at different sites along the epididymis (see Plate 1) were dissected free of the surrounding capsule; liquid paraffin oil, kept at $32^{\circ} \mathrm{C}$, was allowed to flow slowly over the surface of the tissue.

Micropipettes were made from thin-walled glass capillary tubing $(0.85 \mathrm{~mm}$ o.d., $0.085 \mathrm{~mm}$ wall thickness: Clarke Electromedical Instruments, Reading, U.K.) by using a horizontal puller, the tapered end cut and ground to a tip diameter of 40-60 $\mu \mathrm{m}$ with a stone grinding wheel or a metal wheel grinder (Hampel, Max-Planck Institut für Biophysik, Frankfurt, W. Germany) covered in diamond paste (Winter diaplast $\mathrm{N} 0.25$, water and alcohol soluble). The micropipette, filled with liquid paraffin stained with Sudan black (Ullrich et al., 1969), was inserted using a micromanipulator (Leitz, Luton, U.K.) into the tubule and approximately $100 \mathrm{nl}$ seminiferous tubular or epididymal luminal contents were collected. Rete testis fluid and spermatozoa were collected from the rat by the method of Tuck, Setchell, Waites \& Young (1970) as modified by Setchell \& Main (1975).

\section{Motility measurements}

The sperm suspension collected from each site was transferred into a droplet of phosphatebuffered saline (Dulbecco 'A' tablets: $140 \mathrm{~mm}-\mathrm{NaCl}, 0.3 \mathrm{~mm}-\mathrm{KCl}, 0.8 \mathrm{~mm}-\mathrm{Na}_{2} \mathrm{HPO}_{4}, 0.2 \mathrm{~mm}$ $\mathrm{KH}_{2} \mathrm{PO}_{4}, \mathrm{pH} 7.3$ : Oxoid $)$, warmed to $32^{\circ} \mathrm{C}$, and positioned in the sample chamber $(0.24 \mathrm{~mm}$ deep) of a membrane slide which allows diffusion of oxygen into the sample (see Dott \& Foster, 1979). The spermatozoa were observed at $\times 10$ magnification by dark-ground illumination and an area of approximately equal concentration of spermatozoa on the slide was chosen visually for each sample (see also 'Discussion').

The motility of spermatozoa was measured with a Quantimet (Imanco Model 720) image analyser (Cambridge Instrument Co., Melbourn, Herts, U.K.). The machine was programmed to measure over a 30-sec period the frequency of change of area occupied by the spermatozoa which is related to the overall motility of the sample, and not necessarily to either the percentage of motile spermatozoa or the motility of individual cells. Motility can thus be expressed in 'areachange frequency' units or ACF motility values (see Dott \& Foster, 1979). The ACF motility value in each sample was measured at $0,5,10$ and $15 \mathrm{~min}$ after collection. Two samples were removed from each site and each sample was measured in duplicate.

Initially, it was intended to sample from 8 sites along the epididymis in each rat (Plate 1). The sites were distinguished as follows: the duct in Site 1, the initial segment, is very narrow and sufficient sample could not be collected; Site 2, proximal caput epididymidis, was at the highest point of the distinct hump seen when the epididymis is viewed from the side; Site 3, distal caput epididymidis, was as near as possible to the transverse artery and vein found where the epididymis begins to narrow; Site 4, mid-corpus epididymidis, was the mid-point of the thinnest region of the corpus; Site 5, distal corpus epididymidis, was a site on the bulbous region of the cauda epididymidis just before the tubule diameter increases; Site 6, proximal cauda epididymidis, was the mid-point on the bulbous region; Site 7, distal cauda epididymidis, was where the tubule has a larger diameter than that in Site 6 and has not yet uncoiled to form the single unconvoluted tubule of the ductus deferens; Site 8, ductus deferens, corresponded to a site approximately $1 \mathrm{~cm}$ along the duct away from the epididymis. Because of the dramatic differences in the ACF motility values observed between Sites 2 and 3 in the first two rats examined, two further sites, Sites $2 \mathrm{a}$ and $2 \mathrm{~b}$, were identified equidistant between Sites 2 and 3 . Samples were removed from Sites $2 \mathrm{a}$ and $2 \mathrm{~b}$ as well as the other 7 sites from 3 rats. In another 


\section{PLATE 1}

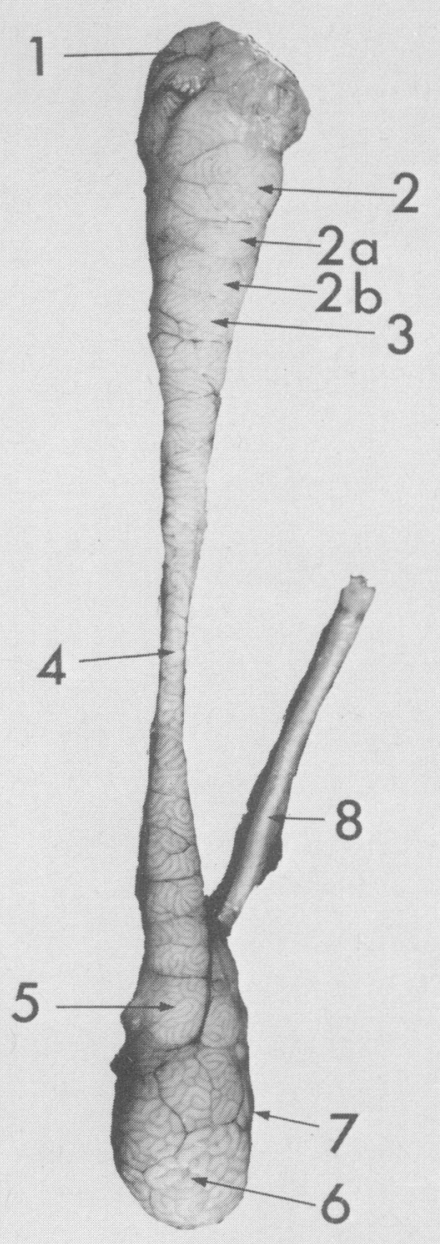

Photograph of a rat epididymis showing the sites referred to in the text for removal of sperm samples; Site 2, proximal caput; Sites $2 a$ and 2b, caput; Site 3, distal caput; Site 4, mid-corpus; Site 5, distal corpus; Site 6, proximal cauda; Site 7, distal cauda; Site 8, ductus deferens. Samples could not be removed from the initial segment (Site 1). 
group of 4 rats the ACF motility value was estimated for the spermatozoa collected from the rete testis.

The time from removal of the sample to the first measurement was always less than 2 min. When problems were encountered during micropuncture, the subsequent ACF motility value of that sample was often very much less than if the micropuncture went smoothly; only the latter results have been included. Because of the technical difficulties encountered during sampling and the length of time involved in measuring the ACF motility value over the 15 -min period for each sample, the rat was anaesthetized often for several hours. We were concerned that the duration of the anaesthesia might affect the motility of the spermatozoa, and this was checked by examination of two samples from the proximal cauda epididymidis (Site 6), one taken at the beginning and the other at the end of each experiment. This check was made on all animals.

\section{Calculations}

The ACF motility values at each site and for each rat were analysed by two-way analysis of variance for each time and for the difference between the values at time 0 and those at 5,10 and $15 \mathrm{~min}$. The data were analysed in two groups. The first group consisted of the ACF motility values of samples from Sites 2 to 8 , excluding $2 a$ and $2 b$, and the second group consisted of the ACF motility values of samples removed from Sites $2,2 \mathrm{a}, 2 \mathrm{~b}$ and 3 .

The data were arranged in two tables to show the mean ACF value for each sample site and at each time. From the analysis, the standard error of the difference of the mean was calculated and the difference was considered significant if any two means in a line differed by twice the standard error.

\section{Results}

Spermatozoa from the seminiferous tubules and rete testis showed no measurable motility either immediately after collection or after $15 \mathrm{~min}$ in vitro. Motility was seen in spermatozoa from the proximal caput epididymidis but the ACF motility value was always less than that of spermatozoa from the other regions. The values for the spermatozoa from the distal regions of the caput to the distal corpus epididymidis were similar at 0 min although those for spermatozoa from the cauda and ductus deferens were always slightly greater (Tables 1 and 2).

\section{Group 1}

During incubation, there was an increase in the ACF motility value of the sample from the proximal caput epididymidis from 0 to $10 \mathrm{~min}(0.01<P<0.001)$. There were no significant changes during the 15 -min period for spermatozoa from the distal caput or distal corpus. The

Table 1. ACF motility values (see text) of spermatozoa removed from sites (see Plate 1) along the epididymis of the rat (Group 1)

\begin{tabular}{rcccccccc}
\hline $\begin{array}{c}\text { Time } \\
\text { (min) }\end{array}$ & $\begin{array}{c}\text { Proximal } \\
\text { caput } \\
\text { (Site 2) }\end{array}$ & $\begin{array}{c}\text { Distal } \\
\text { caput } \\
\text { (Site 3) }\end{array}$ & $\begin{array}{c}\text { Mid- } \\
\text { corpus } \\
\text { (Site 4) }\end{array}$ & $\begin{array}{c}\text { Distal } \\
\text { corpus } \\
\text { (Site 5) }\end{array}$ & $\begin{array}{c}\text { Proximal } \\
\text { cauda } \\
\text { (Site 6) }\end{array}$ & $\begin{array}{c}\text { Distal } \\
\text { cauda } \\
\text { (Site 7) }\end{array}$ & $\begin{array}{c}\text { Ductus } \\
\text { deferens } \\
\text { (Site 8) }\end{array}$ & s.e.* \\
\hline 0 & 8.92 & 55.33 & 57.58 & 51.08 & 66.83 & 76.08 & 67.67 & $2 \cdot 6^{* * *}$ \\
5 & 12.42 & 58.75 & 47.92 & 53.33 & 59.42 & 64.50 & $60 \cdot 83$ & $4 \cdot 0^{* * *}$ \\
10 & 18.33 & 52.67 & 44.92 & 52.00 & 52.00 & 62.58 & 53.83 & $4.4^{* * *}$ \\
15 & 15.42 & 55.08 & 40.25 & 46.52 & 46.67 & 54.83 & $55 \cdot 17$ & $5 \cdot 6^{* * *}$ \\
\hline
\end{tabular}

* s.e. $=$ standard error of the difference of the means (see text), for 3-5 observations at each point.

${ }^{* * *} P<0.001$, for any two means in the row which differ by more than twice the s.e. 
ACF motility values decreased between 0 and 5, 0 and 10 and 0 and $15 \min (0.01<P<0.05$; $0.001<P<0.01 ; P<0.001$ respectively) in the samples from the mid-corpus and between 0 and 10 and 0 and $15 \mathrm{~min}(0.001<P<0.01 ; 0.001<P<0.01$ respectively) from the proximal cauda. In the distal cauda and ductus deferens samples there were decreases in ACF values from 0 to $10 \min (0.001<P<0.01 ; P<0.001$ respectively) (Table 1$)$.

\section{Group 2}

The ACF motility values did not differ greatly between Sites $2 b$ and 3 although in contrast to those in the first group (Table 1) there was a slight decrease after $15 \mathrm{~min}$ from the Site 3 sample. There was an increase in the ACF motility value of spermatozoa from Site $2 \mathrm{a}$ between 0 and 5 min and 0 and $10 \min (0.001<P<0.01 ; 0.001<P<0.01$ respectively) (Table 2).

There were no consistent differences in the ACF motility values of the spermatozoa from the proximal cauda epididymidis at the beginning and end of the experiment in any of the rats.

Table 2. ACF motility values (see text) of spermatozoa removed from sites (see Plate 1) along the caput epididymidis of the rat (Group 2)

\begin{tabular}{cccccc}
\hline Time (min) & $\begin{array}{c}\text { Proximal caput } \\
\text { (Site 2) }\end{array}$ & $\begin{array}{c}\text { Caput } \\
\text { (Site 2a) }\end{array}$ & $\begin{array}{c}\text { Caput } \\
\text { (Site 2b) }\end{array}$ & $\begin{array}{c}\text { Distal caput } \\
\text { (Site 3) }\end{array}$ & s.e.* \\
\hline 0 & 17.50 & $43 \cdot 17$ & 53.08 & $56 \cdot 83$ & $2 \cdot 8^{* * *}$ \\
5 & 23.83 & 63.33 & 49.50 & 60.08 & $3 \cdot 5^{* * *}$ \\
10 & 26.58 & 54.00 & 55.00 & 52.75 & $4 \cdot 2^{* * *}$ \\
15 & 11.00 & 51.83 & 40.75 & 44.80 & $8 \cdot 1^{* *}$ \\
\hline
\end{tabular}

${ }^{*}$ s.e. $=$ standard error of the difference of the means (see text). for 3-5 observations at each point.

${ }^{* *} P=0.01{ }^{* * *} P<0.001$ for any two means in the row which differ by more than twice the s.e.

\section{Characteristics of movement}

The spermatozoa removed from the proximal caput epididymidis were 'sluggish' during the first 3-5 min of observation but from then on, a circular non-progressive type of movement could be seen. In the next five sites (from caput $2 \mathrm{a}$ to distal corpus), this circular pattern of movement gradually changed (after only a few minutes in the caput and almost immediately in the distal corpus sample) to an undulating, progressive movement. The movement of spermatozoa from the cauda and ductus deferens was characterized by intense, forward and criss-cross movements immediately after dilution as reported by Blandau \& Rumery (1964). Initially, groups of spermatozoa moved together because their heads were adherent. After $5 \mathrm{~min}$ these groups dissociated and more individual sperm movement was observed. Thereafter, the spermatozoa tended to interconnect, forming a web of immotile spermatozoa, and only a few remained attempting to penetrate this web.

\section{Discussion}

This study is probably the first to use an objective measurement of the motility of spermatozoa removed from precise sites along the epididymis of the rat (in contrast to counting the percentage of spermatozoa that are motile). The samples collected were free of contamination from surrounding tissue, blood and other extracellular fluid which may have interfered with the motility measurements. Our findings have confirmed the previous results (Blandau \& Rumery, 1964; Burgos \& Tovar, 1974; Wyker \& Howards, 1977) that rat spermatozoa first become motile in the caput but subsequently acquire the capacity to move in a forward direction in the distal regions of the epididymis. The spermatozoa acquire the capacity for motility in a very 
limited part of the epididymis; completely immotile and fully motile (but non-progressive) spermatozoa can be recovered from sites very near to one another in the caput epididymidis, a matter of several tubular diameters apart on the surface. Similar observations have been reported for the rabbit (Gaddum, 1968).

We have no explanation for the gradual decrease with time of the ACF motility values of the caudal and ductal samples; this contrasts with the maintenance of the ACF motility value of the spermatozoa from the corpus and distal caput epididymidis and the gradual increase in the ACF motility value in those from the proximal caput epididymidis. The spermatozoa from the cauda and ductus deferens were more active than the others and they may have exhausted their energy reserves more quickly, but we cannot exclude the possibility of accumulation of toxic metabolites such as lipid peroxides (see Jones \& Mann, 1977a, b).

Previous workers have found that the spermatozoa removed from the epididymis are immotile when held in their natural environment and become motile only when they are diluted with buffer (Morton, Harrigan \& Jooss, 1973; Wyker \& Howards, 1977). Morton et al. (1973) have further suggested that, in the hamster, calcium ions play an important role in the transformation in vitro of quiescent spermatozoa to fully active motile spermatozoa. In the rat, spermatozoa taken from the proximal caput epididymidis take about $10 \mathrm{~min}$ to show maximal motility but in other samples full motility was seen immediately when mixed with calcium-free buffer. The luminal fluid collected from the rat epididymis is extremely viscous and contains a large number of spermatozoa; either characteristic may simply impede movement of the individual spermatozoa which will only be seen to be motile when diluted with buffer. In contrast, spermatozoa from the cauda epididymidis of the monkey and rabbit are very motile when collected by a micropipette and held in their natural environment (B. T. Hinton, unpublished observations; R. Jones, personal communication). This may reflect, in the rabbit at least, the lower concentration of spermatozoa in the cauda epididymidis when compared to that of the rat (Jones \& Glover, 1973; B. T. Hinton, unpublished observations). Indeed, in all samples from rats in the present study, spermatozoa in areas of high density were immotile whereas those in areas of low density in the same sample on the membrane slide were extremely active. This was the main reason why areas of approximately equal sperm concentration were chosen in different samples.

Whatever the explanation for the differences in vitro, it is clear that as the spermatozoa move along the epididymis in vivo they develop the potential for motility. The development of motility may be due to ageing of the spermatozoa (Young, 1931; Bedford, 1975) or, as suggested by Burgos \& Tovar (1974), to some factor or factors not present in the proximal region of the caput epididymidis but present in the more distal regions. Our studies on the composition of fluid removed from various sites along the epididymis (B. T. Hinton, A. M. Snoswell \& B. P. Setchell, unpublished data) suggest that carnitine may be one of these factors. Until studies similar to those reported here have been carried out on the motility of spermatozoa held by ligatures in the proximal caput epididymidis (Site 2), it is not possible to say whether ageing or specific factors are the more important.

We thank Dr R. Jones for valuable comments and suggestions on the text. This investigation received financial support from the World Health Organization.

\section{References}

Bedford, J.M. (1975) Maturation, transport, and fate of spermatozoa in the epididymis. In Handbook of Physiology, Section 7: Endocrinology, Vol. 5: Male Reproductive System, pp. 303-318. Eds D.W. Hamilton \& R. O. Greep. American Physiology Soc., Washington, D.C.
Blandau, R.J. \& Rumery, R.E. (1964) The relationship of swimming movements of epididymal spermatozoa to their fertilising capacity. Fert. Steril. 15, 571-579.

Burgos, M.H. \& Tovar, E.S. (1974) Sperm motility in the rat epididymis. Fert. Steril. 25, 985-991.

Dott, H.M. \& Foster, G.C. (1979) The estimation of 
sperm motility in semen, on a membrane slide, by measuring the area change frequency with an image analysing computer. J. Reprod. Fert. 55, 161-166.

Fray, C.S., Hoffer, A.P. \& Fawcett, D.W. (1972) A reexamination of motility patterns of rat epididymal spermatozoa. Anat. Rec. 173, 301-308.

Gaddum, P. (1968) Sperm maturation in the male reproductive tract: development of motility. Anat. Rec. 161, 471-482.

Jones, R. \& Glover, T.D. (1973) The collection and composition of epididymal plasma from the cauda epididymidis of the rabbit. J. Reprod. Fert. 34, 395403.

Jones, R. \& Mann, T. (1977a) Toxicity of exogenous fatty acid peroxides towards spermatozoa. J. Reprod. Fert. 50, 255-260.

Jones, R. \& Mann, T. (1977b) Damage to ram spermatozoa by peroxidation of endogenous phospholipids. J. Reprod. Fert. 50, 261-268.

Morton, B., Harrigan, J. \& Jooss, T. (1973) The activation of motility in quiescent hamster sperm from the epididymis. Biol. Reprod. 9, 71-72 Abstr.

Setchell, B.P. \& Main, S.J. (1975) The blood-testis barrier and steroids. In Hormonal Regulation of
Spermatogenesis, pp. 223-233. Eds F. S. French, V. Hansson, E. M. Ritzen \& S. N. Nayfeh. Plenum Press, New York.

Tournade, A. (1913) Difference de motilité des spermatozoides prélèvés dans les divers segments de l'epididyme. C. r. Séanc. Soc. Biol. 74, 738-739.

Tuck, R.R., Setchell, B.P., Waites, G.M.H. \& Young, J.A. (1970) The composition of fluid collected by micropuncture and catheterisation from the seminiferous tubules and rete testis of rats. Pflügers Arch. ges. Physiol. 318, 225-243.

Ullrich, K.J., Frömter, E. \& Bauman, K. (1969) Micropuncture and microanalysis in kidney physiology. In Laboratory Techniques in Membrane Biophysics, pp. 106-129. Eds H. Passow \& R. Stämpfli. SpringerVerlag, Berlin.

Wyker, R. \& Howards, S.S. (1977) Micropuncture studies of the motility of rete testis and epididymal spermatozoa. Fert. Steril. 28, 108-112.

Young, W.C. (1931) A study of the function of the epididymis. III. Functional changes undergone by spermatozoa during their passage through the epididymis and vas deferens in the guinea-pig. $J$. exp. Biol. 8, 151-162.

Received 9 May 1978 